\section{CASES OF CHILDREN.}

To the Editor of THe Lancet.

SIR:-If you deem the following cases worthy of record, they are at your service for insertion. I am, Sir, your obedient servant,

Walworth, Aug. 12th, 1837.

E. Crisp.

IMPERTIOUS COLON.

CASE 1.-July 20th, 1834. I attended Mrs. A., East-lane, Walworth, with her sixth child; the labour was short, and the child at birth appeared perfectly healthy, but after a few hours it began to vomit a dark-coloured fluid; the vomiting continued at intervals for about 24 hours, when the infant died. The bowels were not relieved.

I examined the body 20 hours after death, and the following were the appearances:-

The small intestines were much distended with air' the peritoneal coat was congested; the rectum and colon not larger than a common sized gcose quill; the mucous lining covered with a white pulpy matter; the colon, at about an inch and a half from the coecnm, terminated in a perfect cul-de-sac, beyond which the intestine was impervious to the extent of half an inch. No morbid change was observed in any other part.

OBSTRUCTION OF THE CYSTIC DUCT.

CASE 2.-July 5th, 1837. I delivered Mrs. S., Vassal-road, Brixton, of a fine and apparently healthy girl. The child remained well until the 8th, when a yellowish tinge was observed on the skin, which gradually increased; on the 10th the bowels were frequently relieved; the motions were yellow and watery; the child often drew its legs up towards the abdomen, and appeared to suffer pain, but continued to take the breast until the evening (10th), when the mother observed a sudden change in the symptoms; the face and extremities became cold, the breathing hurried, and death took place at 80 'clock on the following morning.

Examination of the body 24 hours after death.

$\mathrm{My}$ attention was first directed to the gall-bladder, which $I$ found quite empty, the surrounding parts being tinged with bile: about one-sixth of an inch from the commencement of the cystic duct I observed a hard, yellow protuberance, about the size of a pea, between which and the neck of the gall-bladder was an ulcerated opening, through the duct, which would admit the end of a common sized blow-pipe; the edges of this opening were thin, and of a livid appearance; the hepatic and common ducts were quite pervious, and the structure of the liver healthy ; the stomach contained a little curdled milk, and the intestines a small quantity of yellow mucus; the peri- toneum was not inflamed; indeed, the morbid condition of the cystic duct was the only discoverable deviation from healthy structure.

I removed the gall-bladder with the ducts, and, after making a more minute examination, I found the protuberance to consist of hard inspissated bile, on the removal of which the duct on the intestinal side was readily distended with the blow-pipe.

Remarks.-I conceive that the above cases are interesting, as shewing that death may arise from causes which cannot even be guessed at without having recourse to a post-mortem examination. I believe there are but few, if any, cases on record similar to the one last described. The cystic and common ducts had been obstructed by calculi, \&c., for a considerable period, but I think that ulceration in consequence is of rare occurrence. The symptoms clearly pointed out the changes which were going on during life. The intestines were plentifully supplied with bile from the common duct; the greater part of the bile in the gall-bladder was taken up by the absorbents, and hence the yellow state of the skin. The opening, probably, took place on the evening before death; the cause of this opening, I imagine, being the imperfect supply of blood to the part, arising from the great distention of the duct, and consequent pressure of its vessels; the livid appearance of the parts around the ulceration would, I think, warrant such a conclusion.

\section{ANOTHER SPECIMEN}

OF THE

\section{EXAMINATIONS AT APOTHECA- RIES' HALL.}

\section{To the Editor of The LANCET.}

SIR :-I am happy to see that the Professor of Medicine, in the University College, has at length denounced the system pursued in the examination of students at the Apothecaries' Hall, a system which has long been painfully known to the junior branches of the profession. When $I$ was a student, eight or nine years ago, it was the common talk of the school to which I belonged. In my examination before the worshipful body of " Grandes Doctors doctrina," "De la rhu. barbe et du senć," I must acknowledge that I did not experience any of the very ungentlemanlike conduct complained of by so many. The first very undignified remark which occurred during my examination, was, when I was asked the process for making extract of elaterinm; I had forgotten it, and immediately said so; my examiner pressed the question, and $I$ then said that $I$ had not been mployed in the practical part of pharmacy. 